\title{
Experiencias B-learning con Apps de Arte en la asignatura de Educación Plástica, Visual y Audiovisual: logotipo y stopmotion como armas de construcción masiva
}

\author{
Martín Caeiro Rodríguez - Universidad Internacional de La Rioja (UNIR) D0000-0001-5616-3747 \\ Cristina Navarrete Artime - Universidad de Oviedo \\ (D) 0000-0002-3001-0678
}

Recepción: 23.05.2020 | Aceptado: 30.06.2020

Correspondencia a través de ORCID: Martín Caeiro Rodríguez $\quad$ iD 0000-0001-5616-3747

Citar: Caeiro, M y Navarrete, C (2020). Experiencias B-learning con Apps de Arte en la asignatura de Educación Plástica, Visual y Audiovisual: Logotipo y stopmotion como armas de construcción masiva. REIDOCREA, 9, 107-120.

Financiación: Este proyecto ha sido financiado por la Universidad Internacional de La Rioja-UNIR en la convocatoria "PROYECTOS DE INVESTIGACIÓN EXCELENCIA UNIR 2018/2020". Título proyecto: "ARTS and APPS: aplicaciones digitales y educación artística." Código: B0036-1819

Resumen: Este trabajo presenta los resultados de dos experiencias formativas resultado de una colaboración entre la Universidad y un Instituto de Educación Secundaria en la asignatura de $4^{\circ}$ curso de Educación Plástica, Visual y Audiovisual incorporando Apps de Arte y procesos digitales a los procesos expresivos como complemento a los analógicos. Para ello, se identificaron contenidos en la programación anual susceptibles de trabajarse incorporando Apps de Arte y en línea con el proyecto eTwinning "Armas de construcción masiva", procediendo a continuación al diseño de las acciones. Estas experiencias se elaboraron conforme a una ficha de actividades tanto para Logotipo como Stop Motion. Los alumnos empezaron a trabajar desde procesos físicos analógicos para progresivamente ir incorporando las Apps seleccionadas y las posibilidades digitales. Para cerrar el proceso se pasó un cuestionario de evaluación a los alumnos. Los resultados en cada una de las experiencias ofrecen imágenes y resultados sobre los recorridos tanto analógicos como digitales enriquecedoras en línea con el modelo Blended Learning. Lo ocurrido durante los procesos evidencian la necesidad de que los alumnos experimenten previamente con diferentes apps, tanto las seleccionadas por el docente como las de libre descubrimiento y que cuenten con dispositivos individuales desde el inicio de curso que den estabilidad a las experiencias.

\section{Palabra clave: Apps}

B-learning experiences with Art Apps in the subject of Plastic, Visual and Audiovisual Education: Logo and stopmotion as weapons of mass construction

\begin{abstract}
This work presents the results of two training experiences resulting from a collaboration between the University and a Secondary Education Institute in the 4th year subject of Plastic, Visual and Audiovisual Education incorporating Art Apps and digital processes to the expressive processes as a complement to the analogical ones. To this end, contents were identified in the annual programme that could be worked on by incorporating Art Apps and in line with the eTwinning project "Weapons of mass construction", and then the actions were designed. These experiences were developed according to an activity sheet for both Logo and Stop Motion. The students began to work from physical analogue processes to progressively incorporate the selected Apps and digital possibilities. To close the process an evaluation questionnaire was passed to the students. The results in each of the experiences offer images and results on both the analog and digital paths in line with the Blended Learning model. What happened during the process shows the need for students to experiment previously with different apps, both those selected by the teacher and those of free discovery and to have individual devices from the beginning of the course that give stability to the experiences.
\end{abstract}

\section{Introducción: entre la presencialidad y lo digital en artes}

Las experiencias artísticas en las aulas escolares y preuniversitarias han ido incorporando tecnologías digitales progresivamente, modificando y adaptando sus procesos de enseñanza y aprendizaje. Dentro de los diferentes modelos pedagógicos que incorporan lo digital, encontramos el blended learning o aprendizaje mixto, caracterizado por ser al mismo tiempo físico y digital y que conjuga a través del proceso formativo lo multisensorial y corporal propio del arte con las posibilidades del contexto 
Cibernético, Internet y la Web 3.0 (Abad, 2010, Berenguer, 2003, Burbules, 2014, Escaño, 2010, Giráldez, 2013, Gómez y Sáez, 2012, Marín, 2011, Papadakis, Kalogiannakis y Zaranis, 2017, Saura, 2011, Wainewright, 2005). En la actualidad, el auge de los dispositivos digitales y la multiplicación exponencial de las Apps ha hecho que emerjan nuevas posibilidades de trabajo, tanto para el docente como para los discentes. En este contexto, encontramos las Apps de Arte, que son aquellas que se han pensado y diseñado para llevar a cabo experiencias artísticas o que permiten trabajar contenidos de arte. El uso de Apps en educación artística ha ido adquiriendo cada vez más protagonismo encontrando diferentes estudios que reflexionan en el contexto artístico educativo su valor para la innovación docente (Rico, 2017, Hernández, 2014, Vincent, 2013, Kortabitarte et Al., 2017). Es en este contexto de aprendizaje mixto que incorpora recursos y procesos digitales a los físicos y analógicos donde diseñamos y situamos nuestras experiencias.

\section{Objetivos}

El objetivo del presente trabajo es analizar y presentar los resultados de dos experiencias formativas b-learning fruto de una colaboración entre la Universidad Internacional de La Rioja y el Instituto de Educación Secundaria Doctor Fleming de Oviedo en la asignatura de Educación Plástica, Visual y Audiovisual que incorporan Apps de Arte durante los aprendizajes. Para ello se analizan los procesos analógicos y digitales desde el punto de vista de sus interacciones a partir del uso de Apps de Arte por parte del alumnado; se seleccionan varias Apps a partir de una matriz de evaluación; identificamos las necesidades y posibilidades surgidas durante los procesos de creación; finalmente, se evalúan las impresiones de los discentes a través de un cuestionario diseñado para estas experiencias.

\section{Métodos: descripción de las experiencias educativas}

\section{Contexto y destinatarios}

El contexto de experimentación es el aula de arte, campo al que los investigadores tienen acceso desde el inicio de curso por tratarse una de las autoras de la profesora que imparte la materia. El alumnado participante en ambas propuestas formativas está formado por 16 estudiantes (14 alumnas y 2 alumnos) que cursan $4^{\circ}$ de Educación Secundaria dentro de la materia Educación Plástica, Visual y Audiovisual (EPVA). La experiencia se inicia en el mes de enero de 2020, una vez que las familias del alumnado participante han firmado el consentimiento de uso de imágenes de sus hijos, y cuando el alumnado está comenzando a iniciarse en el proyecto europeo 'Armas de construcción masiva'. Este proyecto europeo eTwinning tiene como objetivo fomentar el uso de la palabra, el conocimiento, la cultura, la ciencia, la amistad, las artes... como armas y herramientas para detectar, combatir y erradicar la violencia. En él participan docentes de diversas disciplinas y de diferentes países (Bulgaria, Francia, Italia, España). Esta temática de violencia resulta fundamental para sensibilizar al alumnado de $4^{\circ}$ de la ESO aportando a las experiencias un valor de transversalidad formativa.

\section{Técnicas e instrumentos}

Aunque nuestro trabajo incide en la innovación formativa tanto desde la perspectiva de las estrategias que usa el docente como de las experiencias que ponen en juego los discentes durante el aprendizaje mixto, estas se relacionan con el enfoque etnográfico (Bolivar, 1998), ya que llevamos a cabo una observación participante de las actividades realizadas por el alumnado utilizando la documentación fotográfica propia de la Investigación Basada en Imágenes (IBI), para registrar, tanto las experiencias como los 
trabajos de los discentes (Sullivan, 2004, Hernández, 2008, Marín-Viadel y Roldán, 2019). Asimismo, se deja constancias de la observación participante en un diario de campo en el que registramos las impresiones del alumnado respecto a las tareas que se plantean, analizando sus logros y dificultades y pudiéndole así acompañar durante todo el proceso productivo atendiendo a sus necesidades y conociendo día a día sus evoluciones (Díaz de Rada, 2011).

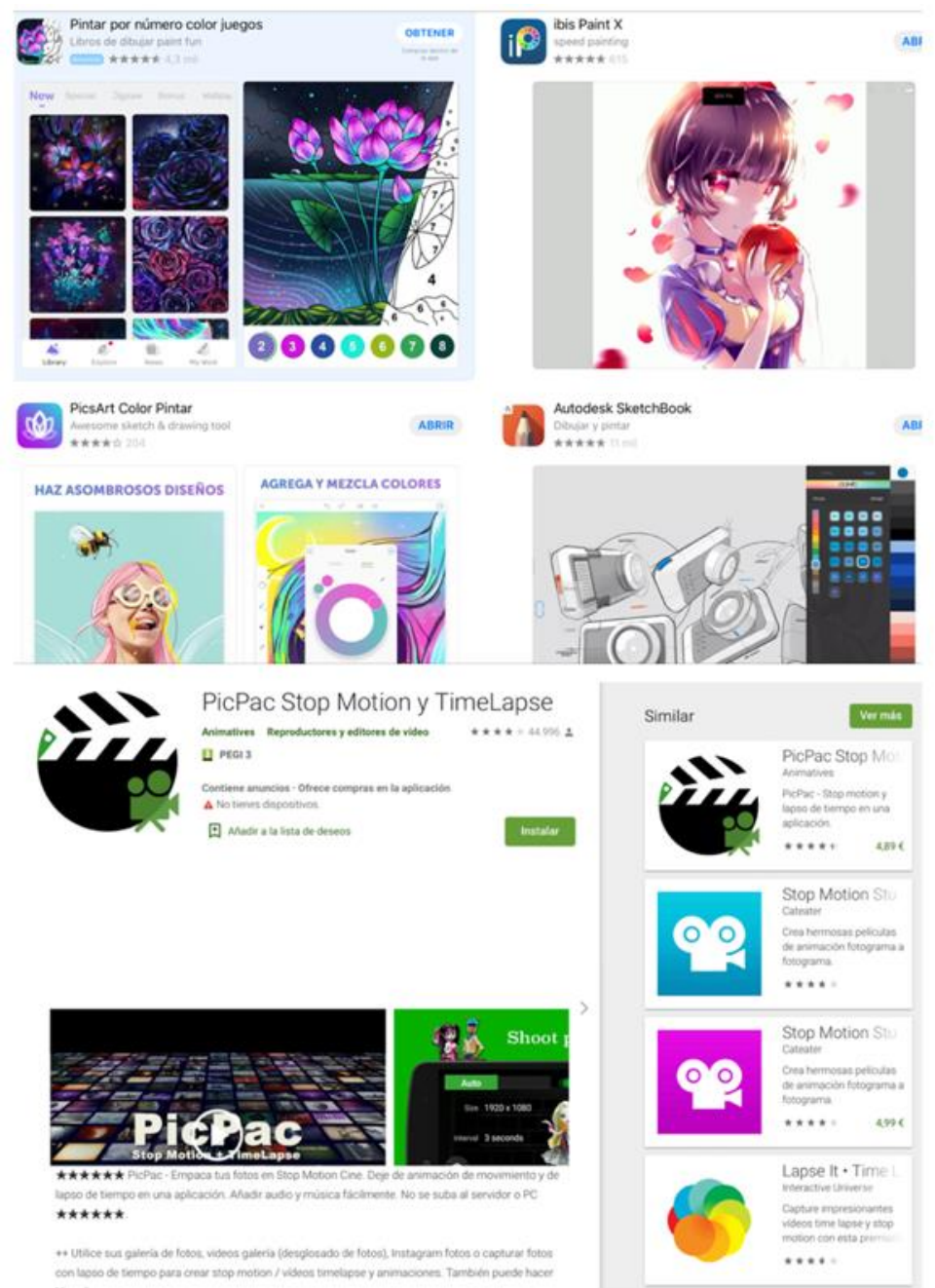

Figura 1. Algunas Apps expresivas para Logotipo (arriba) y para stop motion (abajo)

Pedagógicamente nos situamos en el modelo del Aprendizaje Basado en la Creación Artística, conforme a los objetivos de aprendizaje de la asignatura en la que ocurren las experiencias y donde la subjetividad del discente aporta valor al resultado y al proceso mismo del aprender. Asimismo, se aplicó una evaluación comprensiva a las Apps (Stake, 2006), que es aquella en la que los evaluadores de los recursos se guían por la experiencia y se basan en gran medida en la interpretación personal. La selección de Apps para estas experiencias se ha acometido a partir de un instrumento de evaluación (Caeiro et Al., 2020; Caeiro, 2020) que contempla para su valoración tres dimensiones: artística (diferenciando el dominio expresivo y el dominio perceptivo), técnica y pedagógica. Finalmente, se utilizó un cuestionario diseñado para recoger las impresiones generadas por la incorporación de Apps por parte del alumnado una vez finalizadas ambas experiencias formativas. 


\section{Procedimiento de las experiencias}

El desarrollo de las dos experiencias siguió los siguientes pasos:

- Identificación de las tecnologías digitales con las que cuenta el centro educativo

- Experimentación comprensiva por los docentes con diferentes Apps y evaluación según el instrumento de evaluación

- Uso de Ficha de actividad Arts and Apps

- Introducción con los grupos a las experiencias en torno al proyecto eTwinning "Armas de construcción masiva" y su página web

- Desarrollo de los proyectos por parte de los diferentes grupos con pautas y seguimiento del docente en dos fases: a) procesos analógicos y b) procesos digitales

- Paso al trabajo online individual de los alumnos por confinamiento

- Documentación visual de las experiencias

- Uso de rúbrica de evaluación para las actividades de los alumnos

- Entrega de cuestionario de evaluación a los alumnos

- Análisis de resultados

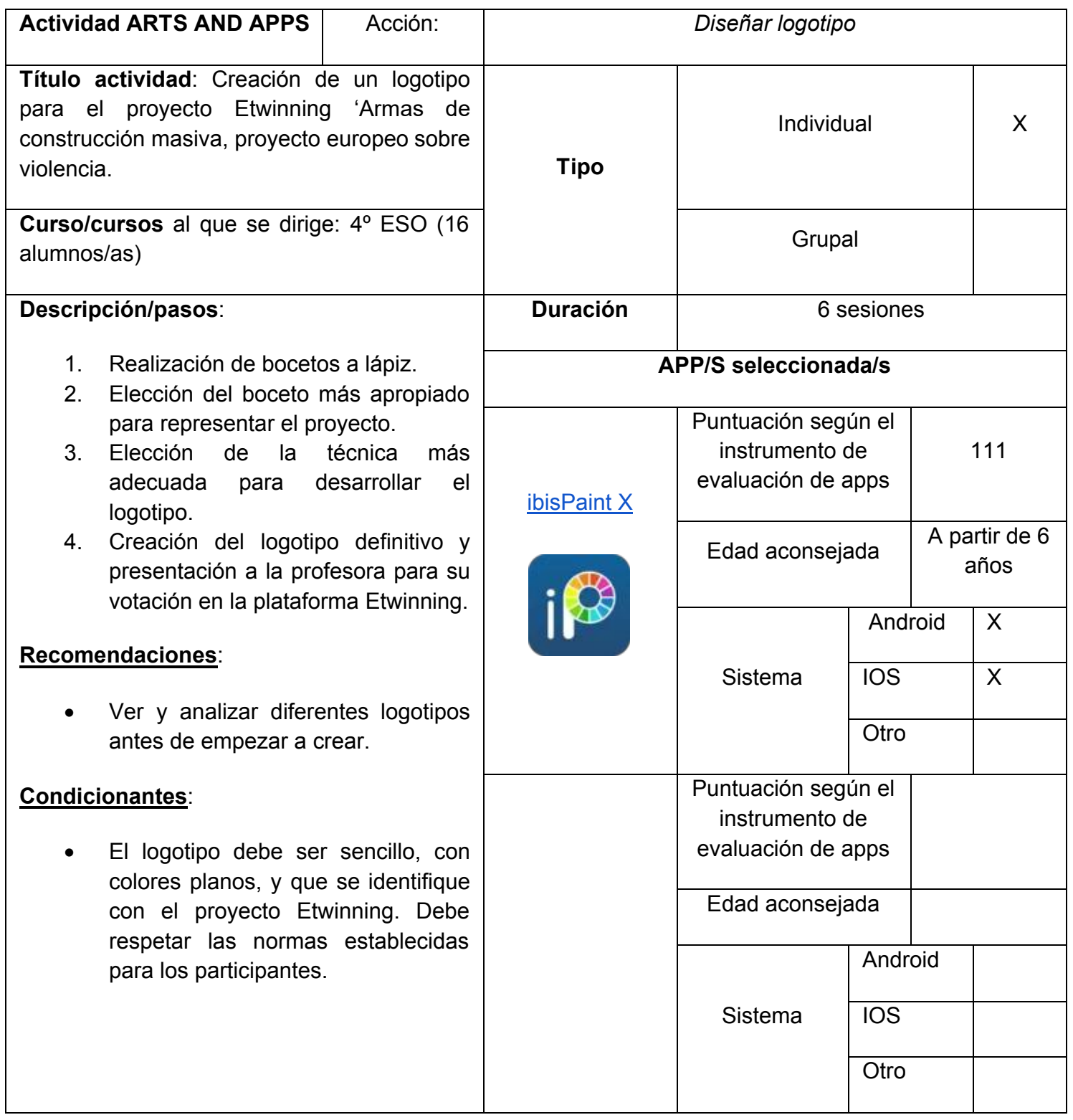




\begin{tabular}{|c|c|}
\hline Recursos & $\begin{array}{ll}\text { - } & \text { Dispositivos digitales: smartphones y tabletas } \\
\text { - } & \text { Blog de la asignatura: (Autora 2) para publicar las } \\
\text { instrucciones y los trabajos finales } \\
\text { - } & \text { Padlet, Twitter y Página eTwinning } \\
\text { - } & \text { Otros materiales: lápices, rotuladores, etc. }\end{array}$ \\
\hline $\begin{array}{l}\text { Objetivos didácticos (se } \\
\text { recomienda de } 1 \text { a } 3 \\
\text { máximo) }\end{array}$ & $\begin{array}{l}\text { Se extraen del Bloque 3. Fundamentos del diseño (BOE, 2015) } \\
\text { - Elaboración de un proyecto de diseño gráfico, considerando los } \\
\text { factores que intervienen en el proceso de creación: } \\
\text { presupuestos iniciales, investigación y recopilación de } \\
\text { información, bocetos iniciales, presentación de soluciones, } \\
\text { realización, maqueta y evaluación. } \\
\text { Experimentación, mediante los elementos visuales, } \\
\text { conceptuales y relacionales del lenguaje visual, de las } \\
\text { posibilidades y propiedades expresivas de las técnicas gráfico- } \\
\text { plásticas aplicadas al diseño. }\end{array}$ \\
\hline $\begin{array}{l}\text { Contenidos artísticos (se } \\
\text { recomienda de } 1 \text { a } 3 \\
\text { máximo) }\end{array}$ & $\begin{array}{l}\text { - Conoce y planifica las distintas fases de realización de la imagen } \\
\text { corporativa de una empresa. } \\
\text { - Realiza composiciones creativas y funcionales adaptándolas a las } \\
\text { diferentes áreas del diseño, valorando el trabajo organizado y } \\
\text { secuenciado en la realización de todo proyecto, así como la exactitud, el } \\
\text { orden y la limpieza en las representaciones gráficas. } \\
\text { - Utiliza las nuevas tecnologías de la información y la comunicación para } \\
\text { llevar a cabo sus propios proyectos artísticos de diseño. }\end{array}$ \\
\hline
\end{tabular}

Figura 2. Ficha actividad Logotipo

\begin{tabular}{|c|c|c|c|c|c|c|}
\hline \multicolumn{2}{|c|}{\begin{tabular}{|l|l|} 
Actividad ARTS AND APPS & Acción: \\
\end{tabular}} & \multicolumn{5}{|c|}{ Editar vídeo } \\
\hline \multicolumn{2}{|c|}{ Título actividad: Stopmotion sobre violencia. } & \multirow[b]{2}{*}{ Tipo } & \multicolumn{3}{|c|}{ Individual } & $\mathrm{X}$ \\
\hline $\begin{array}{l}\text { Curso/cursos al que se dirige } \\
\text { alumnos/as) }\end{array}$ & ESO (16 & & \multicolumn{2}{|c|}{ Grupal } & & $x$ \\
\hline \multicolumn{2}{|l|}{ Descripción/pasos: } & Duración & \multicolumn{4}{|c|}{6 sesiones } \\
\hline \multicolumn{2}{|c|}{$\begin{array}{l}\text { Visionado del vídeo "Le llamaban } \\
\text { chuleta de cerdo" o "To This Day } \\
\text { Project". }\end{array}$} & \multicolumn{4}{|c|}{ APP/S seleccionada/s } & \\
\hline \multicolumn{2}{|c|}{$\begin{array}{l}\text { Project". } \\
\text { 2. Formar equipos ( } 4 \text { o } 5 \text { personas). } \\
\text { 3. Creación de una película de }\end{array}$} & \multirow{5}{*}{$\underline{\text { sotpmotion }}$} & \multicolumn{2}{|c|}{$\begin{array}{c}\text { Puntuación según el } \\
\text { instrumento de evaluación } \\
\text { de apps }\end{array}$} & \multicolumn{2}{|c|}{120} \\
\hline \multirow{5}{*}{\multicolumn{2}{|c|}{$\begin{array}{ll}\text { a. Idea general del relato. } \\
\text { b. } & \text { Descomposición de la idea } \\
& \text { en varios planos: storyboard. } \\
\text { c. } & \text { Selección de los recursos } \\
& \text { necesarios: objetos, dibujos, } \\
& \text { escenarios, maquillaje y } \\
& \text { vestuario. } \\
\text { d. Selección de la App más } & \text { apropiada para el trabajo en } \\
& \text { función del material. Edición } \\
\text { y presentación final del } \\
\text { ejercicio. }\end{array}$}} & & \multicolumn{2}{|c|}{ Edad aconsejada } & \multicolumn{2}{|c|}{$\begin{array}{c}\text { A } \\
\text { partir } \\
\text { de } 3 \\
\text { años }\end{array}$} \\
\hline & & & \multirow{3}{*}{ Sistema } & \multicolumn{2}{|c|}{ Android } & $\mathrm{x}$ \\
\hline & & & & \multicolumn{2}{|l|}{ IOS } & \\
\hline & & & & \multicolumn{2}{|c|}{ Otro } & \\
\hline & & & \multicolumn{2}{|c|}{$\begin{array}{c}\text { Puntuación según el } \\
\text { instrumento de evaluación } \\
\text { de apps }\end{array}$} & \multicolumn{2}{|c|}{66} \\
\hline
\end{tabular}




\begin{tabular}{|c|c|c|c|c|c|}
\hline \multirow{2}{*}{\multicolumn{2}{|c|}{$\begin{array}{l}\text { Recomendaciones: } \\
\quad \text { Dejar clara la pos } \\
\text { la violencia que se }\end{array}$}} & \multirow{4}{*}{$\frac{\text { Viva video }}{20}$} & \multicolumn{2}{|l|}{ Edad aconsejada } & $\begin{array}{c}\text { A } \\
\text { partir } \\
\text { de } 12 \\
\text { años }\end{array}$ \\
\hline & & & \multirow{3}{*}{ Sistema } & Android & $\mathrm{X}$ \\
\hline \multirow{12}{*}{\multicolumn{2}{|c|}{$\begin{array}{l}\text { - Cada equipo debe realizar una película } \\
\text { de } 2 \text { minutos de duración como mínimo } \\
\text { utilizando una media de } 6 \text { imágenes } \\
\text { por segundo. La técnica es libre. } \\
\text { - Usar diferentes tipos de } \\
\text { plano/encuadre: primerísimo primer } \\
\text { plano, plano detalle, plano general, } \\
\text { plano medio.... } \\
\text { - Usar la angulación para dar sentido a } \\
\text { la narración audiovisual. } \\
\text { La corrección del ejercicio se realiza a } \\
\text { través de una rúbrica de evaluación } \\
\text { accesible online. }\end{array}$}} & & & IOS & $x$ \\
\hline & & & & Otro & \\
\hline & & \multirow{5}{*}{$\frac{\text { Stop Motion }}{\text { Studio }}$} & $\begin{array}{l}\text { Puntuación según el } \\
\text { instrumento de } \\
\text { evaluación de apps }\end{array}$ & \multicolumn{2}{|c|}{35} \\
\hline & & & Edad aconsejada & \multicolumn{2}{|c|}{$\begin{array}{l}\text { A partir de } 8 \\
\text { años }\end{array}$} \\
\hline & & & & Android & $\mathrm{X}$ \\
\hline & & & Sistema & IOS & $\mathrm{X}$ \\
\hline & & & & Otro & \\
\hline & & \multirow{5}{*}{ Flipa Clip } & $\begin{array}{l}\text { Puntuación según el } \\
\text { instrumento de } \\
\text { evaluación de apps }\end{array}$ & 78 & \\
\hline & & & Edad aconsejada & $\begin{array}{l}\text { A partir } \\
\text { de } 7 \\
\text { años }\end{array}$ & \\
\hline & & & \multirow{3}{*}{ Sistema } & Android & $\mathrm{X}$ \\
\hline & & & & IOS & $x$ \\
\hline & & & & Otro & \\
\hline Recursos & \multicolumn{5}{|c|}{$\begin{array}{l}\text { Dispositivos digitales: smartphones y tabletas } \\
\text { Blog de la asignatura: (Autora 2) para publicar las instrucciones y los } \\
\text { trabajos finales }\end{array}$} \\
\hline $\begin{array}{l}\text { Objetivos didácticos (se } \\
\text { recomienda de } 1 \text { a } 3 \\
\text { máximo) }\end{array}$ & \multicolumn{5}{|c|}{$\begin{array}{l}\text { Se extraen del bloque 2: Lenguaje audiovisual y multimedia (BOE, 2015) } \\
\text { - Experimentación a través de las técnicas de expresión gráfico- } \\
\text { plástica aplicadas a la animación e interactividad, para producir } \\
\text { y transformar imágenes visuales con diferentes intenciones. } \\
\text { - Aplicación de la imagen animada en formas multimedia. } \\
\text { - Utilización de las Tecnologías de la Información y la } \\
\text { - Comunicación en las propias producciones. } \\
\text { Análisis de la imagen: las características visuales y los } \\
\text { significados de las imágenes. }\end{array}$} \\
\hline $\begin{array}{l}\text { Contenidos artísticos (se } \\
\text { recomienda de } 1 \text { a } 3 \\
\text { máximo) }\end{array}$ & \multicolumn{5}{|c|}{$\begin{array}{l}\text { - Realiza un storyboard a modo de guión para la secuencia de una } \\
\text { película. } \\
\text { - Realiza, siguiendo el esquema del proceso de creación, un proyecto } \\
\text { personal. }\end{array}$} \\
\hline
\end{tabular}

Figura 3. Ficha actividad Stopmotion 


\section{Resultados: de las implicaciones intersubjetivas a las variaciones durante el proceso}

\section{Proceso del ejercicio de creación de un logotipo}

La creación de un logotipo que represente el proyecto colaborativo "Armas de construcción masiva" se presenta al alumnado con el objetivo de trabajar los contenidos de la materia que se relacionan con el diseño gráfico al mismo tiempo que se da una respuesta a una necesidad práctica. Para ello se presentan al alumnado las bases del concurso que se desarrolla entre los 21 centros participantes en el proyecto europeo. En estas bases no se propone ninguna técnica especifica lo que da al alumnado múltiples posibilidades, aunque sí se especifica que el ejercicio debe ser individual y se acota la temática que debe estar relacionada con las características del proyecto: 'multidisciplinar e internivelar, tiene como objetivo principal fomentar el uso de la palabra, el conocimiento, la cultura, la ciencia, la amistad, las artes... como armas y herramientas para detectar, combatir y erradicar la violencia." (https://www.etwinning.net/es/pub/index.htm) Como en todo proceso de diseño, se invita al alumnado a comenzar esbozando ideas poco elaboradas hasta seleccionar, en una segunda fase, las técnicas más apropiadas para el ejercicio final. Para esta primera fase todo el alumnado participante se decanta por las técnicas más tradicionales, el papel y el lápiz, que les permiten la creación de bocetos rápidos. En una segunda fase de desarrollo una de las alumnas comienza ya a experimentar con la aplicación Ibis Paint $X$ que habíamos propuesto, para pasar sus bocetos a un formato más elaborado digitalmente. Los buenos resultados obtenidos por esta alumna, que ya conocía la aplicación, hacen que el resto de los compañeros se animen a trabajar con ella en sus propios dispositivos móviles para probar a realizar en formato digital los trabajos que, en algunos casos, tenían prácticamente terminados ya en papel. Los resultados obtenidos se publican posteriormente en el blog de la profesora y en el Twinspace del proyecto, donde todo el alumnado participante en este proyecto europeo puede votar de forma anónima el logotipo que prefiera.
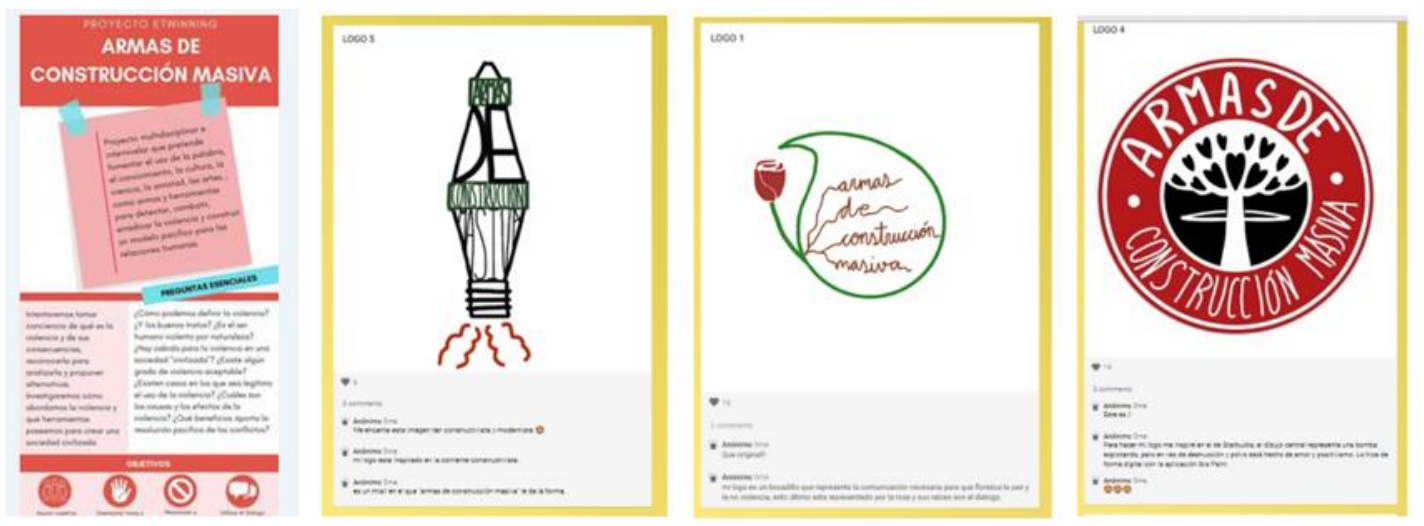

Figura 4. Proyecto eTwinning (izquierda) y logos hechos con apps expresivas para su votación en Padlet. A la derecha: el logo ganador 
Proceso de desarrollo del ejercicio Stopmotion

Las instrucciones dadas inicialmente fueron estas:

El trabajo que realizaremos en clase usando nuestros dispositivos móviles consistirá en lo siguiente:

- Pensamos en una idea sencilla, una frase bastará para describir lo que va a ocurrir en nuestro corto.

- Desarrollamos la idea en pequeñas viñetas.

- El material para trabajar es libre: papel, juguetes, plastilina, dibujos o incluso nuestro propio cuerpo. Intentaremos crear vida y contar algo a través de nuestras cámaras.

Para la presentación del ejercicio de stopmotion se recurre a varios vídeos explicativos que se alojan en el blog específico del aula, bajo el título: "To This Day Project" (Koyczan, 2013). De esta forma pueden ver la explicación siempre que lo deseen, en qué consiste la técnica stopmotion, así como qué materiales pueden utilizarse. En el mismo artículo online se sugiere al alumnado el uso de la app PicPac o Imovie para dispositivos con sistema IOS. Se explica al alumnado qué posibilidades es recomendable que ofrezca una App para stopmotion: la posibilidad de editar la velocidad (fotogramas por segundo), la opción de disparar ráfagas (especialmente útil si se trabaja con figuras animadas), la opción de trasparentar cada fotografía con respecto a las nuevas fotos (muy útil si trabajamos con objetos). En una sesión posterior, la profesora recuerda al alumnado qué tipos de planos pueden usar según su encuadre y angulación, así como los objetivos de cada uno de ellos dentro del lenguaje cinematográfico. Se recomienda a los estudiantes que utilicen los planos de forma intencionada para conseguir un hilo narrativo coherente. Lo que en la ficha de actividad queda identificado como "condicionantes". El ejercicio debe realizarse de forma cooperativa, por lo que se forman tres equipos, dos de ellos formados por 5 estudiantes y otro con 6 estudiantes.

Al igual que en la actividad del logotipo, el alumnado comienza a trabajar de forma analógica, realizando bocetos sobre papel de cada una de las escenas de cada película. Una vez que los tres equipos tienen claro la trama de historia que van a desarrollar, los personajes y la conclusión comienzan a experimentar con una de las App propuestas, PicPac a través de los dispositivos móviles facilitados por el centro educativo (16 tabletas digitales) o sus propios smartphones. El alumnado, en equipos, prueba las aplicaciones móviles sugeridas e introducen otras que descubren ellos mismos, una vez que los grupos tienen ya los bocetos y la idea que van a desarrollar en la película. Finalmente, los equipos seleccionan y deciden Apps y dispositivos:

- Equipo 1: trabajan con fondos y personajes dibujados o realizados en papel. Usan PicPac con el teléfono móvil.

- Equipo 2: trabajan con personas reales (ellos mismos como actores). Usan VIVaVideo con el teléfono móvil.

- Equipo 3: realizan dibujos a rotulador sobre la puerta de la clase. Usan PicPac con la tableta. Insertan fondos a las figuras que ellos mismos han creado con papel. 

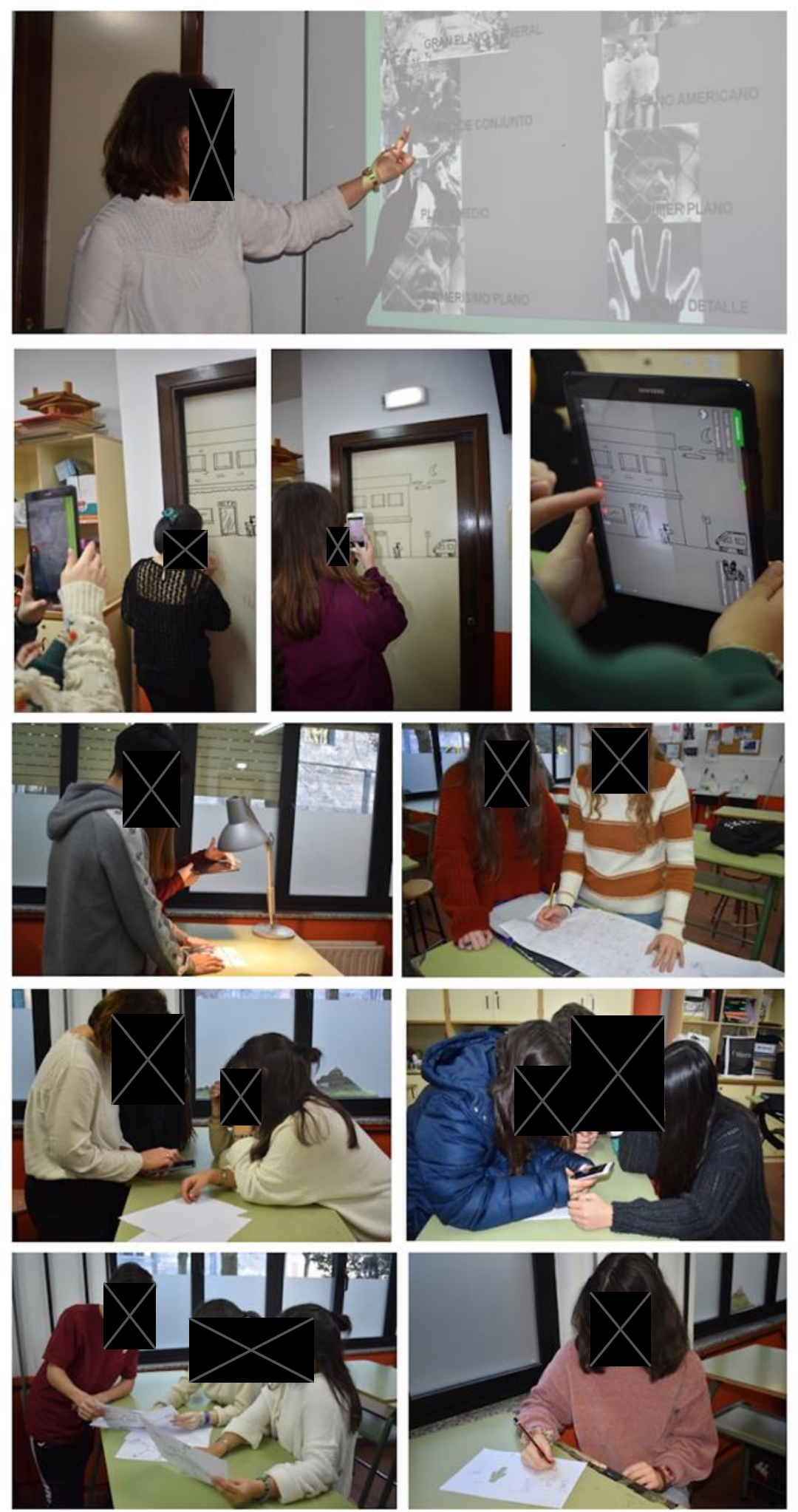

Figura 5. Procesos analógicos y digitales e interacciones cognitivo-sociales en la línea del blendend learning

Esta diversidad de procesos analógicos propios del Stopmotion (Sasiain y Aberasturi, 2018), genera necesidades y ritmos distintos en cada equipo. Según avanzan las sesiones van surgiendo varios problemas, algunos de ellos en relación con las 
dificultades que presentan algunas Apps al usarlas en sus propios dispositivos y otras con las dificultades que presenta el ejercicio en sí mismo en sus aspectos analógicos del proceso que han escogido. El equipo 2 es el que más dificultades encuentra, ya que una vez que tiene fotografiadas las imágenes la aplicación invierte el orden de algunas imágenes, invirtiendo la acción, este problema se soluciona finalmente usando otro dispositivo. Por otro lado, en el equipo 3 surgen problemas con relación al proceso escogido, ya que la creación de fondos de forma manual requiere una gran inversión de tiempo y esfuerzo del alumnado.
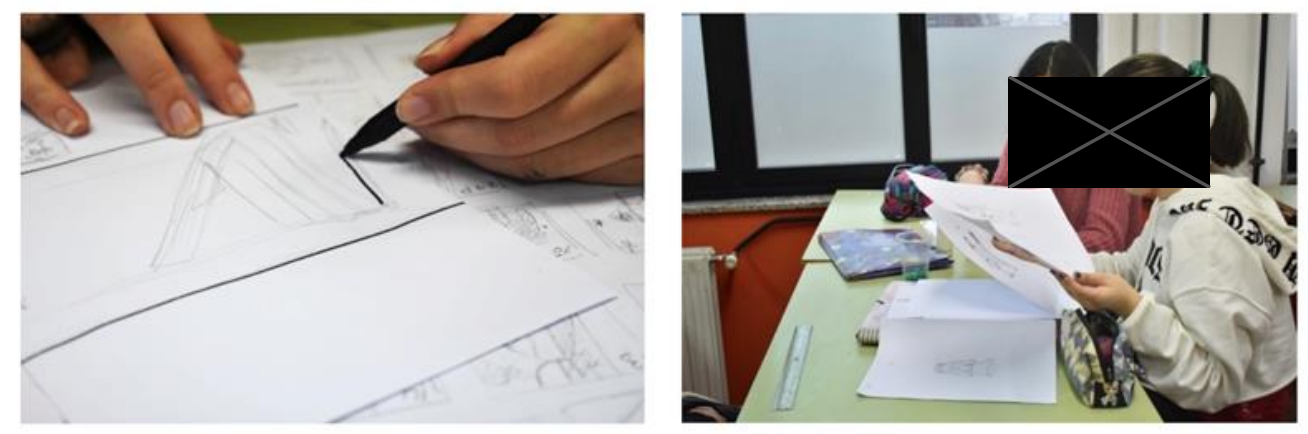

Figura 6. Ejemplo de las posibilidades que ofrece el proceso analógico: grafismo y multidimensionalidad

El confinamiento nos alcanza justo cuando los alumnos están en la fase de montaje. El aislamiento hace que algunos alumnos continúen trabajando en el proyecto de forma individual y abriéndose a nuevas experimentaciones blended-learning de procesos analógicos y Apps de Arte. Los productos finales del alumnado, los diferentes equipos y cortos individuales, se valoran con ayuda de una rúbrica de evaluación online, que previamente se les había dado a conocer y en la que se consideran principalmente cuatro aspectos: los textos y el sonido, el contenido o mensaje, el uso de las imágenes y la animación de las mismas, y por último, el reparto de tareas dentro del grupo.
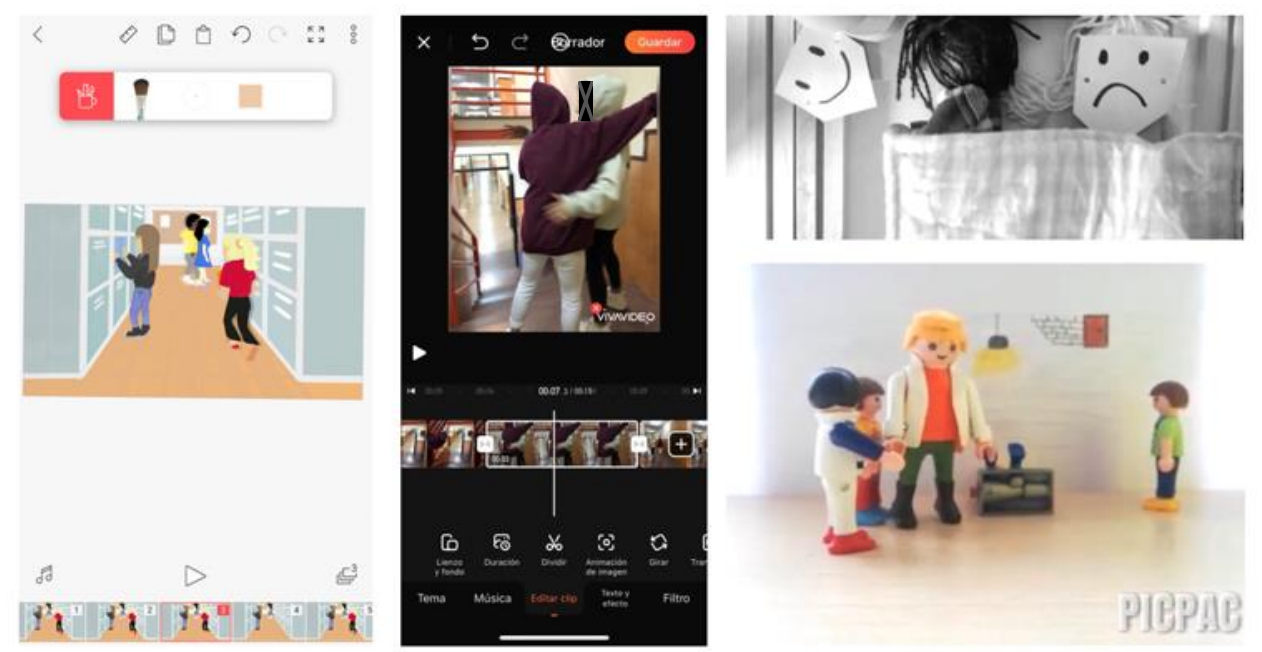

Figura 7. Imágenes de trabajos animación. Izquierda: creación digital (Flipa Clip), Centro y derecha: creaciones analógicas y objetuales (VivaVideo, Stop Motion Studio y Pic Pac) 


\section{Resultado cuestionario uso de Apps de Arte}

En cuanto a la valoración por parte de los alumnos de las experiencias con apps, destacamos que el $66,7 \%$ considera que incrementan su interés por el arte, el $83 \%$ que incrementa el uso artístico de los recursos que ofrecen las Apps de Arte y el 91,7\% que influyen en su motivación para aprender contenidos. Entre las razones de esta motivación indican que "ayuda a motivarse al poder hacer fotos y vídeos", "lo tecnológico se hace más ameno", "el deseo de saber más sobre cómo se usan estas Apps", "el uso de apps es una manera de atraer a las nuevas generaciones para que les guste el arte". Una de las causas de la desmotivación es que "se dispone de medios tecnológicos limitados" o que "de repente empiezan a ir mal por lo que me aburro". También hay que destacar que cuando la App resulta fácil de usar influye en la percepción del alumno e implicación en el proceso. En relación con los aspectos de adecuación o no de las Apps seleccionadas para realizar las actividades, la mayoría responde positivamente. En relación con lo que más gusta al alumnado una vez concluidas las experiencias es lo que aprenden con ellas, la diversión que implica su uso y lo que menos el tiempo que pierden hasta llegar a comprender su funcionamiento o cuando les dan problemas debido a los propios dispositivos. En este sentido, consideran fundamental disponer de tabletas digitales individuales.

\section{Discusión: utilidad de la previsión de las acciones y selección de recursos digitales}

El modelo de aprendizaje mixto es un contexto que genera formaciones, interacciones e informaciones a lo largo de los procesos de creación que va combinando recursos físicos con los digitales, experiencias multisensoriales que enlazan con las posibilidades de las tecnologías digitales. Este modelo nos permite a los docentes no condicionar desde el inicio todo el aprendizaje al recurso digital, en este caso, de la App, algo fundamental cuando no estamos trabajando solo la competencia digital ni haciendo net.art. El aprendizaje mixto también posibilita mayores interacciones entre el alumnado, sea la actividad individual o colectiva, evitando el excesivo aislamiento del alumno por el uso excesivo del dispositivo. En la Figura 6 podemos ver cómo lo físico permite, por ejemplo, desplegar varias hojas, papeles que pueden plegarse, solaparse, descartarse, doblarse... mientras que el dispositivo digital en las primeras etapas del proceso expresivo, esto lo impide reduciendo lo multisensorial y cerrando el camino a experiencias complejas de carácter fenomenológico. A su vez, lo digital permite y posibilita, por ejemplo, el ir hacia atrás y hacia adelante en el proceso, probar rápidamente combinaciones de colores, efectos de trazado... adquiriendo todavía más sentido en el proceso de generar una animación. Las experiencias que hemos programado, situadas en el aprendizaje mixto, han incidido desde su inicio en enlazar aquellos procesos físicos en los que el alumnado experimenta gráfica y plásticamente desde técnicas, herramientas, soportes y procesos multidimensionalmente con las experiencias que solo posibilitan las tecnologías digitales y así lo evidencian los resultados (Figura 7). En esta línea, es importante destacar cómo los alumnos han ido generando diferentes experiencias analógicas fundamentales previas al uso de los dispositivos digitales propias del b-learning, aportando los propios alumnos diversos métodos: dibujar en cristal, dibujar en papel transparente, fotografías, personajes en plastilina, objetos prefabricados, etcétera, dando lugar a interacciones entre los equipos 
y el grupo clase de gran significado cognitivo-social. En cuanto al logotipo, los resultados quedaron marcados por las posibilidades expresivas de la App seleccionada, de ahí que sea necesario conocer y evaluar previamente las Apps para dibujar y pintar. Los alumnos consiguieron enlazar lo visual y expresivo con lo comunicativo logrando logos y animaciones que transmitían el lema marcado: "Armas de construcción masiva".

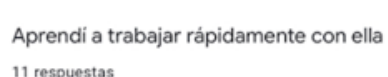
11 respuestas

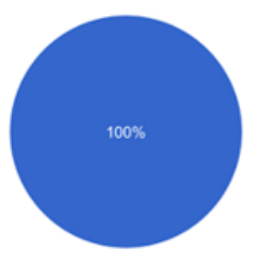

Pude conseguir lo que me propuse

12 respuestas

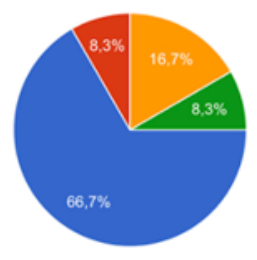

Escogi otra App distinta que me gustó más 12 respuestas

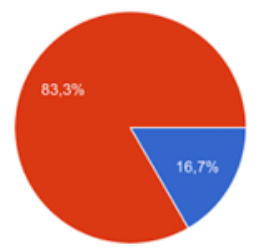

Las actividades que tenia que realizar con la app me motivaban 12 respuestas

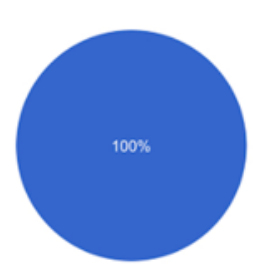

№
Consegui aprender a usarla

12 respuestas

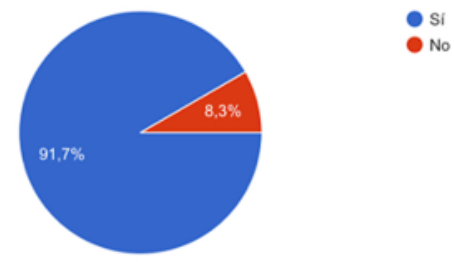

Logré terminar lo que me propuso mi profesor/profesora 12 respuestas
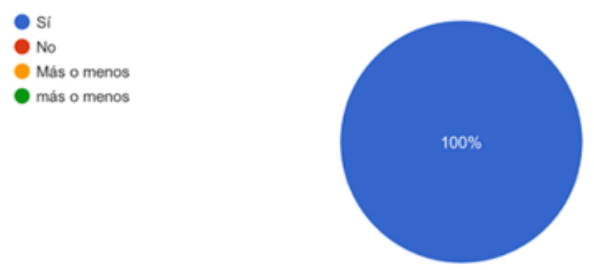

- Si

Me resultó muy complicado entender cómo trabajar con la App

12 respuestas
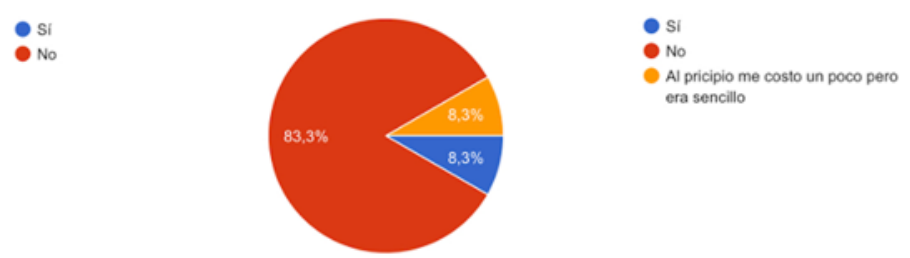

Al pricipio me

El tiempo que me dio mi profesor/profesora para trabajar con la App fue suficiente

12 respuestas

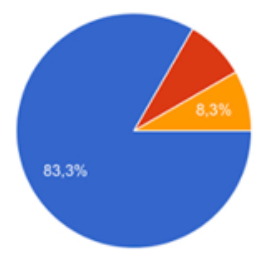

- Si

Si, gracias al atraso de la fecha

de entrega

Figura 8. Resultados gráficos del cuestionario de evaluación de las experiencias

Conclusiones: mejores instrumentos de partida

Algo que nos llamó la atención, fue cómo el alumnado modifica durante el proceso el tipo de Apps previamente seleccionadas según diferentes problemáticas encontradas: desaparición de imágenes sesión a sesión, falta de memoria, de carga, limitaciones de 
la App generadas por su propio dispositivo... Esto refuerza la idea de que contar con un instrumento de evaluación de Apps de Arte favorece ser más eficaces antes y durante las experiencias. Desde la realidad de los centros y los recursos digitales con los que se cuenta, nos encontramos con limitaciones asociadas a los propios dispositivos como tabletas y smartphones que condicionan el desarrollo de las propuestas, así como los resultados que se obtienen. El uso de dispositivos móviles, en este caso las tabletas digitales, que están al alcance de todo el alumnado del centro educativo suponen un problema desde el principio, ya que algunas fotos que realizan los estudiantes para sus trabajos desaparecen al ser eliminadas supuestamente por otros estudiantes, además las Apps no funcionan bien en estos dispositivos porque según el alumnado "van muy lentas". Esto hace que el alumnado se decante por el uso de sus dispositivos móviles personales, que está permitido por el centro para usos formativos. El contar con tabletas digitales individuales puede aumentar la efectividad de los aprendizajes y unos mejores resultados en todos los grupos. Entre las respuestas del alumnado es de destacar cómo el funcionamiento o no de la App les puede motivar o frustrar.

En este sentido, resulta fundamental dotar al profesorado en activo de instrumentos que le permitan prever todas las variables e identificar las posibles variaciones sobre lo programado para que cualquier experiencia obtenga los resultados de calidad artísticos esperados. Es aquí donde el modelo de ficha diseñado exprofeso para este tipo de actividades b-learning que incorporan Apps de Arte en las experiencias, así como el instrumento de evaluación previa de Apps y el cuestionario de evaluación adquieren importancia para el área de educación artística y allí donde se requiera trabajar conjuntamente las competencias artística y digital. El instrumento de evaluación guía la valoración de cada App en sus aspectos artísticos, técnicos y pedagógicos. Asimismo, es fundamental que antes de iniciar las experiencias y seleccionar las Apps de Arte, al análisis del docente se unan las pruebas por parte de los discentes integrando también su percepción y criterio en su selección. Esto permitirá asegurar la funcionalidad en los dispositivos y tener alternativas programadas para sacar más partido tanto a los recursos como a los procesos. Finalmente, debemos identificar los "condicionantes" que lleven las experiencias a una mayor excelencia de los procesos y los resultados, "directrices" pensadas para que la poética implícita en la creación artística se mantenga viva también al incorporar recursos digitales y afloren la singularidad y personalidad característica de las obras artísticas y que no generan en sí las Apps de Arte.

\section{Referencias}

Abad Gómez, R. (2010). Aplicaciones Web 2.0 como recursos didácticos interactivos en los estudios de Bellas Artes. Relada, 4 (4), 249-256.

Berenguer, X. (2003). Arte y tecnología: una frontera que se desmorona. Revista Artnodes, 2, s/p.

Bolívar, A. (Ed.) (1998). La investigación biográfico-narrativa en educación. Guía para indagar en el campo. Granada: Force.

Burbules, N. (2014). Aprendizaje ubicuo: nuevos contextos, nuevos procesos. Revista Entramados - Educación y sociedad, (1), 131-135.
BOE (2015). Real Decreto 1105/2014, de 26 de diciembre, por el que se establece el currículo básico de la Educación Secundaria Obligatoria y del Bachillerato.

Caeiro Rodríguez, M. (2020). Arts and Apps: Aplicaciones digitales y educación artística. Tres instrumentos para trabajar con Apps de Arte. En Sánchez Rivas, E., Colomo Magaña, E., Ruiz Palmero, J. y Sánchez Rodríguez (Coords.), Tecnologías educativas y estrategias didácticas.

Caeiro Rodríguez, M., Ordoñez Fernández, F., Callejón Chinchilla, M. y Castro León, E. (2020). Diseño de un instrumento de evaluación de aplicaciones digitales (Apps) que permiten desarrollar la competencia artística. Píxel-Bit. Revista De Medios y Educación, 58, 7-25. 
Díaz de Rada Brun, A. (2011). El taller del etnógrafo. Materiales y herramientas de investigación en Etnografía. UNED. Madrid.

Escaño González, C. (2010). Hacia una educación artística 4.0. Revista Arte, Individuo y Sociedad, 2(1), 135-144.

eTwinning.net (2020). Portal educativo web. Disponible en: https://www.etwinning.net/es/pub/index.htm

Hernández Hernández, F. (2008). La investigación basada en las artes. Propuestas para repensar la investigación en educación. Universidad de Barcelona: Educatio Siglo XXI, (26), 85-118

Hernández Ramírez, J. (2014). Instrumento para la valoración preliminar del uso de las APPs en educación primaria. En Maquilón Sánchez, J. J., Escarbajal Frutos A., y Nortes Martínez-Artero, R. (Eds.), Vivencias innovadoras en las aulas de primaria. (273-286): Universidad de Murcia

Iglesias, L. (2012). Mobile ART: Apps móviles en el contexto artístico. Blog Mobile Art. Recuperado de: https://bit.ly/2ID3f4Z

Giráldez, A. (2013). Enseñar artes en un mundo digital: diez propuestas para la formación del profesorado. Belo Horizonte, 3(5), 85-104.

Gómez, RA., y Sáez, CM. (2012). La web 2.0 como herramienta didáctica de apoyo en el proceso de enseñanza aprendizaje: aplicación del blog en los estudios de Bellas Artes [Tesis doctoral] Universidad Complutense de Madrid.

Kortabitarte, A., Ibáñez-Etxeberria, A., Luna, U., Vicent, N., Gillate, I., Molero, B. y Kintana, J. (2017). Dimensiones para la evaluación de aprendizajes en APPs sobre patrimonio. Pulso. Revista de educación, 40, 17-33.

Koyczan, S. (2013). To This Day Project [Película] Lugar: Giant Ant. https://www.youtube.com/watch?list=RDCMUCKwpJb8i4HujU YCcHO29pAQ\&v=|tun92DfnPY\&feature=emb_rel_end
Marín García, T. (2011). Experiencia de innovación docente GOUMH: aprendizaje colaborativo en Bellas Artes con APPS de Google (Actas), en Congreso Internacional de Innovación docente. Universidad de Cartagena.

Marín-Viadel, R. y Roldán, J. (2019). A/r/tografía e Investigación Educativa Basada en Artes Visuales en el panorama de las metodologías de investigación en Educación Artística. Arte, Individuo y Sociedad .31(4), 881-895.

Papadakis, S., Kalogiannakis, M., \& Zaranis, N. (2017). Designing and creating an educational app rubric for preschool teachers. Education and Information Technologies, 22(6), 3147-3165.

Puentedura, RR. (2014). Learning, Technology and the SAMR Model: Goals, Processes and Practice, en Congreso ISTE, Atlanta.

Rico Rico, A. B. (2017). Evaluación del uso de las APPs que abordan los procesos creativos en la educación artística formal. (Tesis Doctoral). Universidad de Valladolid.

Sasiain Camarero-Núñez, A. y Aberasturi Apraiz, E. (2018). Pensar pedagógicamente desde el Arte: El Stop Motion como herramienta de trabajo. En: Caeiro Rodríguez, M. (Coord.). Arte, Educación y Pensamiento digital: Educar, crear y habitar en la quinta pared. Egregius Ediciones.

Saura Pérez, Á. (2011). Innovación educativa con TIC en Educación artística, Plástica y Visual. Líneas de investigación y estudios de caso: MAD.

Stake, RE. (2006). Evaluación comprensiva y evaluación basada en estándares. Barcelona: Editorial Graó

Sullivan, G. (2004). Art Practice as research Inquiryn the visual Arts. New York: Teachers College, Columbia University.

Vicent, N. (2013). Evaluación de un programa de educación patrimonial basado en tecnología móvil. (Tesis doctoral). Universidad Autónoma de Madrid.

Wainewright, P. (2005). What to expect from Web 3.0. ZDNet. Recuperado de: https://bit.ly/2kb5E6H 